\title{
Clinical differentiation of Migraine, Cervicocephalic Syndrome and Meniere's Disease
}

Behzad Saberi

Medical Research, Esfahan, Iran

Corresponding Author: Behzad Saberi, Medical Research, Esfahan, Iran.

Received date: October 08, 2021: Accepted date: December 20, 2021: Published date: January 03,2022

Citation: Behzad Saberi, (2022) Clinical differentiation of Migraine, Cervicocephalic Syndrome and Meniere's Disease, Journal of Clinical Otorhinolaryngology 4(1); DOI: 10.31579/2692-9562/037

Copyright: (c) 2022 Behzad Saberi. This is an open access article distributed under the Creative Commons Attribution License, which permits unrestricted use, distribution, and reproduction in any medium, provided the original work is properly cited

\begin{abstract}
Meniere's disease, cervicocephalic syndrome and migraine are relatively common pathologies. It is important for the clinicians to make difference between these pathologies in clinical settings. This is a brief review on the important clues to differentiate these pathologies from each other to make the diagnosis of each one of these pathologies easier.
\end{abstract}

Keywords: migraine; cervicocephalic syndrome; meniere's disease

\section{Summary}

In Meniere's disease, the occurrence of headache is spontaneous while the pain persists for hours and head position changes would not affect such headache episodes. Spinal movements are not limited in Meniere's disease. Vomiting can be seen in such pathology either. Loop diuretics and glucose infusion can be used for treatment. In migraine, the occurrence of headache is the same with Meniere's disease. Spinal movements are not limited and nausea and vomiting can also be seen. Ergotamine alkaloids can be used for treatment in migraine. In cervicocephalic syndrome, headaches have short durations and would be affected by head position changes. Cervical spinal movements are limited and spasm in the cervical muscles can be seen. There is not any episode of nausea or vomiting in cervicocephalic syndrome. Cervical collar and cervical traction can be used for treatment.

Proper diagnosis of migraine, Meniere's disease and cervicocephalic syndrome is important in clinical settings to make appropriate decisions for treatment of such pathologies.

\section{References}

1. Semaan MT, Megerian CA. Ménière's disease: a challenging and relentless disorder. Otolaryngol Clin $\mathrm{N}$ Am. 2011;44(2):383-403

2. Fred HL. The diagnosis of exclusion: an ongoing uncertainty. Tex Heart Inst J. 2013;40(4):379-81

3. Furman JM, Balaban CD. Vestibular migraine. Ann N Y Acad Sci. 2015;80:179-87

4. Korres SG, Balatsouras DG. Diagnostic, pathophysiologic, and therapeutic aspects of benign paroxysmal positional vertigo. Otolaryngol Head Neck Surg. 2004;131(4):438-44

5. L'Heureux-Lebeau B, Godbout A, Berbiche D, Saliba I. Evaluation of paraclinical tests in the diagnosis of cervicogenic dizziness. Otol Neurotol. 2014;35(10):1858-65 
This work is licensed under Creative Commons Attribution 4.0 License

To Submit Your Article Click Here: Submit Manuscript

DOI: $10.31579 / 2692-9562 / 037$
Ready to submit your research? Choose Auctores and benefit from:
i. fast, convenient online submission
ii. rigorous peer review by experienced research in your field
iii. rapid publication on acceptance
iv. authors retain copyrights
v. unique DOI for all articles
vi. immediate, unrestricted online access

At Auctores, research is always in progress.

Learn more auctoresonline.org/journals/journal-of-clinicalotorhinolaryngology 